\title{
PINTURA EPÓXICA: MATERIAL MULTIFUNGIONAL PARA EL DISEÑO INTERIOR
}

\section{EPOXY PAINT: MULTIFUNGTIONAL MATERIAL FOR INTERIOR DESIGN}

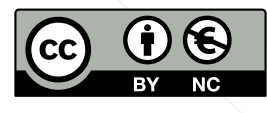

\author{
Diana Paulina Mejía Coronel \\ Universidad de Cuenca \\ Ecuador
}

Diseñadora de Interiores por la Universidad del Azuay. Máster en Gestión y Conservación del Patrimonio Cultural Edificado por la Universidad de Cuenca. Realizó una publicación en el $15^{\circ}$ Seminario Iberoamericano de Arquitectura y Construcción con Tierra titulada "Caracterización constructiva de elementos estructurales en el Bahareque", también en la revista ESTOA titulada "Fotogrametría digital para el levantamiento 3D del sitio arqueológico de Todos Santos, Cuenca (Ecuador)" y en el congreso FORMA 2019 en La Habana con el título "Soluciones interioristas en viviendas de escasos recursos". Docente de la Facultad de Artes - Carrera de Diseño de Interiores de la Universidad de Cuenca.

paulina.mejia@ucuenca.edu.ec

\section{Christian Geovanny Sigcha Cedillo Universidad del Azuay \\ Ecuador}

Diseñador de Interiores por la Universidad del Azuay. Máster en Proyectos de Diseño por la Universidad del Azuay. Conferencista en congreso IDEA de la Facultad de Artes de la Universidad de Cuenca. Tallerista en Terminados, Texturas y Epoxicos en la Facultad de Diseño, Arquitectura y Artes de la Universidad del Azuay. Docente de la Carrera de Diseño Interior de la Facultad de Diseño, Arquitectura y Artes de la Universidad del Azuay.

csigcha@uazuay.edu.ec

Fecha de recepción: 28 de febrero, 2020. Aceptación: 23 de marzo, 2020. 


\section{Resumen}

La presente investigación tiene un enfoque cualitativo con alcance exploratorio y de aplicación. Para realizarla, se inició con la recolección de bibliografía que abarca la historia del material, su evolución y los usos, así como la información técnica necesaria. A continuación, se realizó experimentaciones con el material, se encontró nuevas formas de utilizarlo y maneras más adecuadas de trabajarlo; su aplicación en distintas superficies produce una interesante variedad de resultados con infinidad de posibilidades, que podrían adaptarse a cualquier estilo. Es así que las propiedades físicas y químicas se pusieron a prueba en diferentes superficies y se corroboró sus bondades, logradas en la mayoría, mientras que en pocos casos se reveló sus resultados desfavorables. El proceso fue descrito a detalle y se incluyó fotografías tanto del proceso como de las muestras realizadas. A través de los resultados obtenidos de su aplicación en los ensayos, se demostró que el material puede ser considerado como un revestimiento que brinda nuevas posibilidades. Se evidenció que, por la eficiencia del material, puede ser aplicado en varios ámbitos del diseño y la arquitectura, dando paso a nuevos recursos expresivos a disposición de las manifestaciones contemporáneas y que permiten materializar el producto creativo.

\section{Palabras clave}

Pintura, epóxica, decoración, revestimientos, construcción, terminados.

\section{Abstract}

The present research has a qualitative approach with an exploratory and application scope. The research began with the collection of bibliography that covers the history of the material, its evolution and uses, as well as the necessary technical information. Then, experiments were carried out with the material. New ways of using it and their most appropriate ways of working with it were found; its application on different surfaces produced an interesting variety of results with an infinity of aesthetics which could be adapted to any style. Thus, the physical and chemical properties were tested on different surfaces and their advantages were corroborated by achieving success in most instances, while in a few cases its disadvantages were revealed. The process was described in detail and photographs of both the process and the samples taken were included. Through the results obtained from its application in tests, it was demonstrated that the material can be considered as a coating that offers new possibilities. It was evident that, due to the efficiency of the material, it can be applied in various areas of design and architecture, giving way to new expressive resources available to contemporary manifestations that allow a creative product to materialize.

\section{Keywords}

Painting, epoxy, decoration, coating, construction, finishing details. 


\section{Introducción}

En el mundo arquitectónico, el epóxico es un material que provocó curiosidad tanto por su aplicación, así como por sus resultados. A todo ello se suman sus bondades, su maleabilidad y sus características innatas que permiten obtener productos para conseguir diversidad de productos de diseño; y que, con el tiempo y con mayores estudios, puedan contribuir a materializar nuevas propuestas constructivas. Es por eso que, en el contexto local, se ha podido evidenciar el empleo del producto, como una nueva alternativa innovadora. Se observa que se han generado nuevos usos y tendencias de la mano del diseño.

\section{Materiales y su injerencia en el diseño interior}

El diseño interior conjuga diversas sensaciones que se transmiten a través del volumen del espacio en el que se perciben: formas, texturas, colores y hasta aromas. Cada elemento que en este se inserta produce una relación visual y estética diversa. La propuesta que se realice debe considerar las limitaciones arquitectónicas del lugar, así como entender las correlaciones que se producirán con la inserción de nuevos elementos, que generan continuidades o contrastes con la disposición morfológica de la arquitectura. También producen efectos visuales que pueden emplearse para generar la sensación de amplitud en el espacio o viceversa; el diseñador puede emplear esta estrategia en beneficio de sus propuestas.

El sentido de la vista y del tacto están estrechamente enlazados, existe una reacción psíquica entre los dos. Aunque no se logre tocar algo físicamente, se asume la sensación que esto produce por asociación a los materiales que antes se han palpado. Las texturas que poseen franjas direccionadas pueden acentuar el ancho o la longitud de un plano, en cambio las rugosas hacen parecer un plano más cercano (Ching \& Binggeli, 2015). Por su parte, la escala es un componente a considerar, puesto que la textura de los complementos como mobiliarios 0 accesorios decorativos influyen si se emplean con un material con tramas saturadas. Es decir, en habitaciones grandes las texturas cargadas podrían reducir la sensación de anchura; al contrario, tejidos pequeños podrían generar amplitud en zonas reducidas.
Cada individuo distingue diferentes sensaciones desde su punto de vista, como una experiencia. Rosalind Kranss (1998) analiza el ayuntamiento de Saynatsalo, Finlandia Occidental, y encuentra que las escaleras y sus montantes son de ladrillo, contrastados con el piso de madera de la planta superior. Él relata la percepción de la forma construida que se percibe en el sonido, la textura e incluso en un aroma diferente producido por los diversos materiales y sus tejidos.

También es importante incluir el contraste, porque es un factor que afecta la percepción de los materiales. Es así que, al observar cualquier textura colocada sobre un fondo suave, sobresale más que si se la colocara sobre una superficie con similares características; y al contrario, una suave resalta cuando se contrapone a otra rugosa, incluso disminuyendo la escala de su granulometría (Ching \& Binggeli, 2015).

Es evidente entonces que los materiales son esenciales para la interpretación del espacio y se pueden emplear para generar varias sensaciones que no responden netamente al tacto: pueden evocar profundidad, claridad, oscuridad. Afectan la manera en que los usuarios perciben el ambiente y pueden incluso lograr efectos de amplitud o estrechez.

\section{Historia de los epóxicos y su surgimiento como nuevo material}

El epóxico ha experimentado un rápido avance en el mundo de la construcción. Si bien este producto tuvo un inicio en el campo industrial por el año de 1949, se ha venido abriendo camino en 
el mundo de la construcción. Desde comienzos de la revolución industrial, a mediados del siglo XIX, con la aparición de elementos fundamentales como el hierro y el acero, empieza un mundo interesante en la forma de conservar estos materiales. En la época nace la necesidad de encontrar recubrimientos y protectores que permitan reducir los estragos de la naturaleza, al menos durante un tiempo determinado (Iturralde \& Yagual, 2012). Según se ha visto, los epóxicos provienen de un mundo industrial y empezaron a brindar protección a estructuras u otros elementos constructivos, partes bruscas que también carecían de expresión; estos elementos probablemente encontraron en el material una solución estética, especialmente en revestimientos, ya sean pinturas 0 acabados especiales.

Durante el siglo XX y XXI surgieron los materiales como el plástico y las fibras artificiales que se conformaron dentro de la industria como productos masivos; en esa época surgió la baquelita', como el primer material sintético conformado por fenol formaldehído. Su inventor, Baekeland, descubrió que es un material fluido y que puede ser vertido en moldes para su posterior solidificación. El empleo de los polímeros inició durante la Segunda Guerra Mundial, a través de la fabricación de casetas para equipos de radares electrónicos y también algunas partes de aviones. Esta capacidad de fluidez y posterior solidificación, llamó la atención de los profesionales en el área de la construcción, comenzaron a producir láminas translúcidas que podían tener diversas aplicaciones, tales como cubiertas (Miravete, 1995).

Sus bondades probablemente hicieron que se pudieran resolver muchos problemas en el campo constructivo: desde solucionar problemas en las uniones de hormigón (independientemente de la antigüedad de los dos hormigones) hasta en aquellos detalles en los acabados en el diseño.
El material no solo brinda usos monofuncionales sino que también, por medio de mezclas con otros materiales o por pigmentaciones, ha generado una infinidad de resultados que han permitido ampliar y diversificar su uso; lo que permite obtener resultados estéticos únicos que solamente este tipo de producto puede generar.

Según se ha visto, la resina epóxica surge como una de las derivaciones del polímero con alta empleabilidad en el medio constructivo, puede reaccionar a dos endurecedores: el primero puede agregarse en el proceso de moldeo y necesita calor para su transformación, el segundo desencadena la copolimerización de la resina generalmente a base de ácidos, a base de un agente catalizador: generando muchas posibilidades de usos como pinturas, acabados, adhesivos, aislantes, arte, entre otros (Fernández Cánovas, 1964).

En general, estas resinas poseen baja tracción, buen comportamiento a temperatura elevada y buena resistencia a los agentes químicos (Miravete, 1995). El epóxico se está utilizando cada vez más en el campo constructivo; se obtiene cuando un polímero termoestable se mezcla con un agente catalizador; lo que genera muchas posibilidades de usos (pinturas, acabados, adhesivos, aislantes, arte, etc.) (Fernández Cánovas, 1964).

A partir de este hallazgo, los polímeros aportaron a la fabricación de diversos productos empleados en el campo de la construcción y el interiorismo, lo que incidió en que los diseñadores puedan desarrollar propuestas que anteriormente eran imposibles o demasiado complejas de construir, lo que abrió aún más el abanico de posibilidades en el mundo creativo. En cierta manera, se marcó un antes y un después en el diseño interior. Un aspecto a destacar es que los materiales del medio no tenían capacidades de modelado y transparencias al mismo tiempo, se empezó a aprovechar las virtudes del producto.

\footnotetext{
${ }^{1}$ Baquelita: Fue la primera sustancia plástica totalmente sintética, creada en 1907 y nombrada así en honor a su creador, el belga Leo Baekeland.
} 
Es ahí donde empezó un desarrollo importante en el ámbito de las pinturas: aparecieron los primeros intentos de usar un producto para reducir el deterioro y solventar las necesidades de protección, y emergió un nuevo concepto. La pintura epóxica es un recurso que en la arquitectura y el diseño aporta un gran carácter, permite generar patrones variables y controlables, aporta manifestaciones sensoriales internas o externas. Es decir, es un instrumento generador de diseño que conforma una alternativa importante en la creación de morfologías, aporta características únicas en los espacios.

La técnica y los métodos de uso de las pinturas epóxicas pueden encontrar alternativas que se basen en tendencias. Así se obtienen resultados interesantes como espacios interiores dinámicos y conceptuales, diseños originales, que sean justificables en el ámbito estético y funcional. Incluso, se podría marcar nuevas tendencias conjugando material, color y textura en un solo concepto de modo que se convierta en el intérprete principal, rompiendo en algún grado la estética de una arquitectura dada, logrando nuevos conceptos y significados.

Por medio de la experimentación con el material se alcanzan resultados en el ámbito del uso del producto y sus posibilidades en el interiorismo. Se podrían evidenciar nuevos procesos de diseño, incluso sin explorar todas las bondades del producto, que reflejarán nuevas tendencias y nuevos criterios formales. Es por ello que, en la presente investigación nos enfocaremos específicamente en el uso del epóxico como revestimiento para pintura y acabados.

No se podría explicar el vertiginoso desarrollo de la construcción o del diseño interior sin el uso de recubrimientos 0 acabados. Estructura, mobiliario y espacio serían elementos básicos y precarios que no generarían estímulos positivos en el medio habitable y en la sociedad; la pintura ha jugado un papel importante en el mundo de la construcción. Todo ello con el objetivo de que el diseño y la arquitectura logren obtener nuevos significados 0 interpretaciones, ya que el mundo creativo se encuentra en constante evolución.

\section{Propiedades del producto}

Desde un punto de vista técnico, según Vié (1970) se pueden resaltar propiedades físicas y químicas del material, tales como:

- Alta resistencia química, sobrepasando en gran manera a los materiales tradicionales como el hormigón, el metal o la madera, entre otros. De igual manera, posee una inercia total a los líquidos, solamente los ácidos concentrados logran afectar parcialmente al producto.

- Elevado poder anticorrosivo.

- Propiedades mecánicas que sobrepasan ampliamente al hormigón, de 2 a 3 veces.

- Elasticidad relativamente baja y buen comportamiento ante esfuerzos alternos.

- Baja sensibilidad a las variaciones térmicas.

- Amplia adherencia sobre todos los materiales de construcción como: hormigón, yeso, madera, ladrillo, metales, entre otros.

- Gran resistencia al desgaste y a la abrasión.

- Considerable resistencia eléctrica.

- Bondades decorativas diversas gracias a sus capacidades de pigmentación.

Cabe agregar, que la temperatura es uno de los condicionantes en la trabajabilidad del producto porque afecta su tiempo de endurecimiento (Fernández Cánovas, 1964). En temperaturas frías, el material aumenta su viscosidad y disminuye notablemente su maleabilidad. En este sentido, se debe tener precaución con la humedad, ya que una superficie mojada no permite una correcta homogeneización, disminuyendo las bondades del producto.

Algunos usos de las pinturas epóxicas son a manera de protector, tanto para aislar la corrosión como ligante, mejora la adherencia de capas que se aplicarán posteriormente; en contenedores 0 envases metálicos se utiliza para evitar la oxidación de alimentos. El material también se emplea para diversos terminados: decorativo, revestimiento de alta asepsia (en lugares que requieren permanecer este- 
rilizados) y suelos que requieran alta resistencia. Por su parte, los adhesivos, conocidos como adhesivos estructurales, ligan partes de automóviles, bicicletas y aviones; sus propiedades hacen que sea un adherente para todo tipo de material porque se adapta a casi cualquier situación. Cuando se añade calor al secado del producto, este será mucho más resistente a altas temperaturas.

Las pinturas epóxicas también sirven para elaborar objetos vaciados por su capacidad de maleabilidad, logrando que sea más eficiente en la elaboración de moldes, resulta más económico, es resistente y tarda menos que el moldeado en madera o metal. Al momento de combinar el producto con materiales como la fibra de vidrio o carbono, da como resultados objetos resistentes.

Finalmente, el epóxico en el campo eléctrico sirve para encapsular motores, generadores, transformadores, aisladores u otros; el material también ayuda como un aislante, aplicado en buena parte de componentes con tendencia a cortocircuitos 0 humedad. También, se utiliza para encapsular circuitos integrados, transistores y en la unión de placas; ayuda como aislante y protector a daños provocados por polvo, humedad, entre otros.

En este contexto, es importante destacar la evolución del producto, que, a más de sus avances aplicativos, también presenta avances importantes dentro de su composición química. Actualmente, ya se están implementando epóxicos derivados de compuestos orgánicos tales como el aceite de soya, aceite de linaza, canola, aceite de palma, entre otros. Esta invención es destacable, puesto que, hoy en día casi el 75\%, de la producción mundial de prepolímeros de epoxi se sintetiza por la reacción de condensación de bisfenol y epiclorhidrina (agentes abrasivos). Dichos aceites vegetales se están empleando para la fabricación de resinas de base biológica que, entre muchas de sus ventajas, en comparación con los materiales en base a petróleos, son biodegradables, a precios módicos y poseen excelentes aplicaciones (Kumar, Samal, Mohanty y Nayak, 2018).
Los aceites epoxidados de base vegetal lucen prometedores, por sus características económicas y renovables, para la aplicación industrial. Específicamente, el aceite de soya modificado ha presentado propiedades mecánicas altas, mejores resistencias y aumenta la rigidez en algunas superficies con las que se ha experimentado (Kumar et al., 2018).

Estas resinas orgánicas proporcionan diversas ventajas en relación a las de base petróleo, en especial si se consideran los efectos colaterales que estos últimos producen en la implementación y en su uso posterior. Es conocido que las resinas epóxicas ocasionan alteraciones en la salud de las personas que emplean el material, y provocan, en algunos casos, enfermedades como dermatitis, irritaciones en las vías respiratorias e incluso asma por la inhalación de vapores (UGT, 2020).

Dadas las condiciones que anteceden, se destacan algunos de los momentos de riesgos potenciales del trabajo con el producto, según (García Diez, 2013) son durante: la preparación de la resina, la manipulación de las resinas básicas (sin tratar), el uso de catalizadores y solventes, el proceso de pigmentación. De igual manera, algunas de las sustancias riesgosas al contacto con la piel son: resinas puras, catalizadores o productos de curado y disolventes. También se encuentran las afecciones respiratorias por exposición a emanaciones producidas durante la preparación y polvos de labores de mecanizado.

Es importante mencionar que un buen protocolo de seguridad durante la manipulación de estos productos evita las afecciones mencionadas anteriormente. Adicionalmente, se sugiere trabajar en lugares ventilados 0 , en su defecto, con un buen sistema de ventilación, acompañado del siguiente equipo: mascarillas con filtros para vapores orgánicos, guantes de neopreno, gafas herméticas de goma y, en casos especiales, cremas protectoras. Hay que considerar que, mientras se trabaja con estas sustancias, se debe evitar fumar, comer y beber; también, hay que cuidar de no eliminar de la piel los restos de la 
formulación de la resina compuesta, empleando disolventes, ya que facilita la absorción del producto en los poros y, por consiguiente, los agentes químicos pasarían al torrente sanguíneo (García Diez, 2013).

Por otra parte, nace la preocupación del impacto ambiental que el epóxico ocasiona, ya que los procesos que emplean las industrias para su elaboración, a más de consumir mucha energía también producen compuestos orgánicos volátiles (COV). Las resinas en su estado primario constituyen un riesgo especialmente para organismos acuáticos, causan efectos adversos a largo plazo en su medio ambiente; en estado compuesto son más seguras, generalmente. Por lo tanto, es importante no arrojar restos del material a los vertederos, deben disponerse como residuos peligrosos y enviarse a plantas de reciclaje junto con otros polímeros o plásticos (Ecológico, 2018).

Si consideramos que todos los productos de la construcción ameritan equipos de seguridad para su manipulación y una correcta eliminación de sus desechos, las resinas como tal no constituyen un peligro para la salud ni para el medio ambiente. Tomando todas las recomendaciones y consideraciones, el material podrá ser usado con seguridad e incluso mejorará sus características de sostenibilidad con su entorno; la conciencia ambiental de los usuarios es crucial.

Después de analizar toda la información obtenida sobre este producto, desde el punto de vista constructivo, se puede recopilar algunas propiedades de gran significación para el campo del diseño: óptima adherencia y humectación, buen aislamiento térmico y eléctrico, buena resistencia mecánica, resistencia a la humedad, resistencia al ataque de elementos corrosivos, gran resistencia a temperaturas elevadas, eficiencia en resistencia química, mínima contracción en procesos de curación y excelentes propiedades adhesivas.

\section{Experimentación}

La presente investigación tiene como objetivo evidenciar las bondades que la pintura epóxica presta al mundo del diseño. Hemos visto necesario realizar experimentaciones en diversos tipos de sustratos, para probar algunas propiedades del producto y así plantear nuevas propuestas estéticas en el mundo constructivo. Nos hemos planteado desarroIlar ensayos con materiales de mayor empleabilidad en el medio local, los cuales produjeron interesantes resultados, que podrían aportar en el campo de los profesionales en el ámbito de la arquitectura y el diseño.

Ahora bien, hemos decidido seleccionar las siguientes superficies: madera, hormigón, metal, tela, empastes, cerámica, ladrillo y metal. Elegimos trabajar con los elementos mencionados a manera de muestras pequeñas, con lo que observaremos el comportamiento del producto y la reacción de los distintos sustratos.

En consecuencia, se tomó dos materiales que poseen más aplicación en el medio: la madera y el hormigón. Teniendo en cuenta las evidencias obtenidas en las experimentaciones anteriores, describiremos el proceso necesario a seguir para una correcta aplicación del epóxico. Por lo tanto, este texto se redactó con base en una recopilación de experiencias propias en el que constan sugerencias para su óptima manipulación. 


\section{a.Tratamiento de la superficie previo a la aplicación del producto}

El primer paso para un adecuado uso del material es limpiar la superficie de imperfecciones, lo cual descubrirá daños o deterioros que no permiten una eficiencia en la aplicación de la pintura. Cabe añadir que las principales patologías son agrietamientos, mapeados, mohos, grasas y polvo,s que podrían ser tratados con empastes elastoméricos, sustancias anti hongos o con una limpieza profunda, para optimizar el uso del producto.

Figura 1. Mapeado

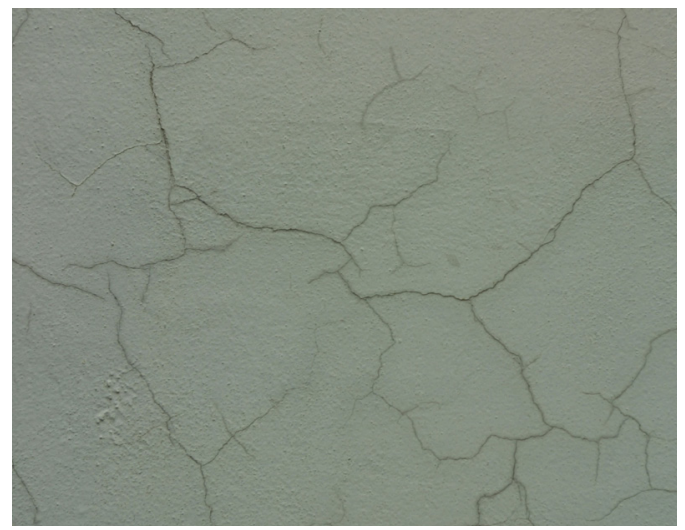

Fuente: Ehow, (2017).

Figura 2. Agrietamiento

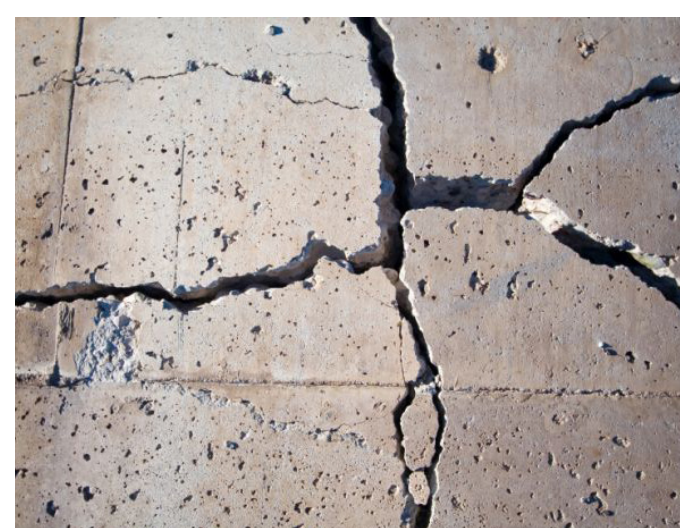

Fuente: Umacon, (2017).
Figura 3. Moho

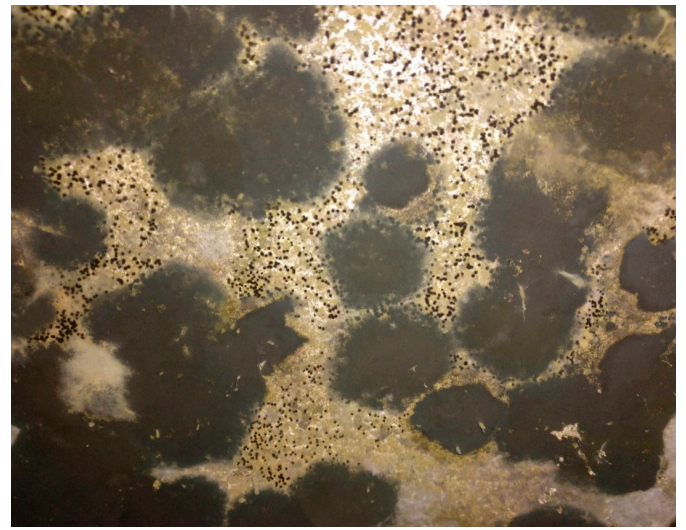

Fuente: Biounit Control, (2019). 


\section{b. Sellado e impermeabilizado de la superficie}

El segundo paso es aplicar un sellado de poros, lo que se consigue con la aplicación de un sellador, ligante 0 un imprimante. El primero se emplea cuando la superficie a trabajar es semirugosa, porque es un polímero medianamente grueso y alisa en buena manera la superficie. Por otra parte, el

Figura 4. Aplicación de sellador en aerosol sobre hormigón

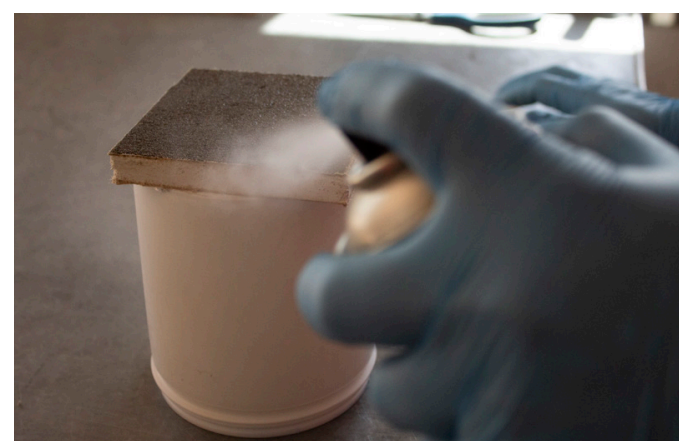

Fuente: Mejía \& Sigcha, (2020).

Figura 6. Aplicación de ligante sobre hormigón

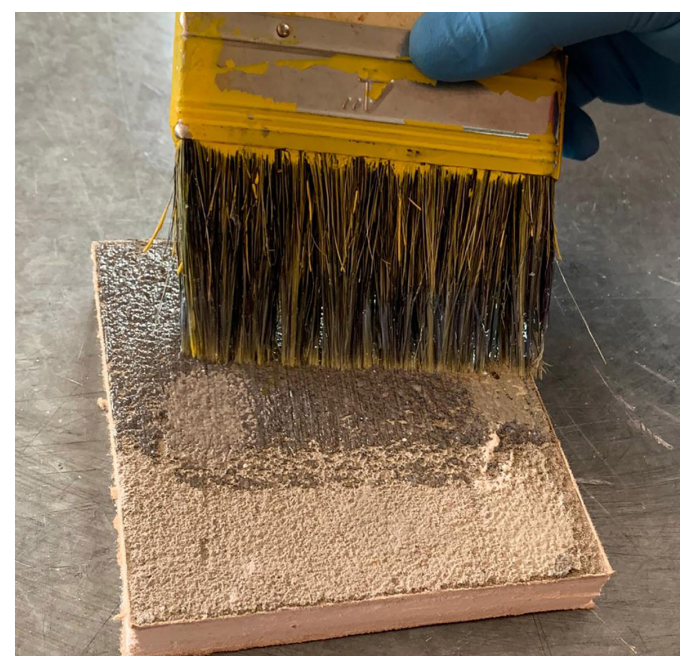

Fuente: Mejía \& Sigcha, (2020). ligante se lo vierte en superficies lisas, ya que estas son pobres en propiedades de adherencia. Por último, los imprimantes son productos que se ocupan en superficies rugosas o propensas a trizaduras.

Después de la aplicación de los productos descritos, se recomienda que el curado de la superficie tenga un período de reposo de al menos 2 a 6 horas, dependiendo de la rugosidad de la superficie trabajada.

Figura 5. Aplicación de sellador en aerosol sobre ladrillo

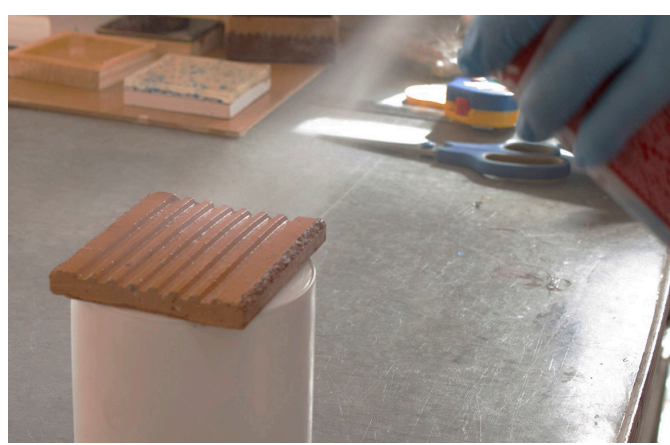

Fuente: Mejía \& Sigcha, (2020).

Figura 7. Aplicación de imprimante sobre hormigón

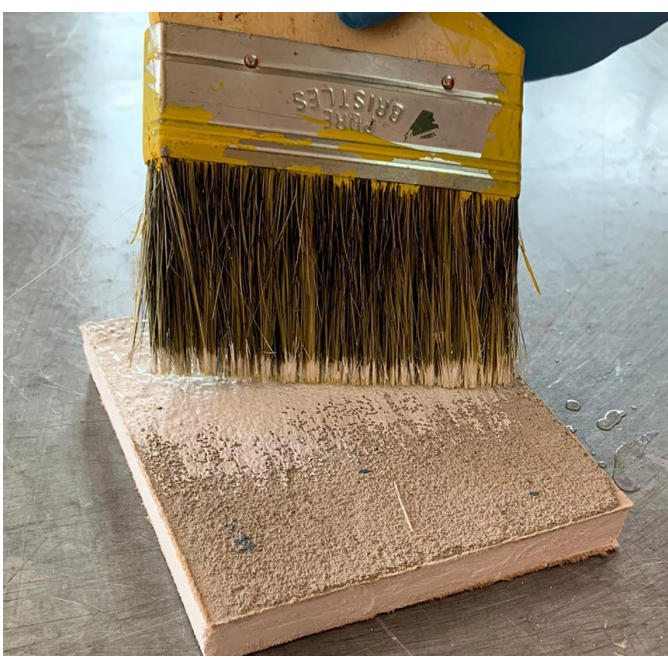

Fuente: Mejía \& Sigcha, (2020) 


\section{c. Recubrimientos}

El tercer paso consiste en aplicar un revestimiento en la zona a tratar. La creatividad de los diseñadores influye en gran manera en esta sección; es la parte del proceso donde se experimenta ampliamente, se podrían utilizar los materiales más comunes de la construcción tales como ladrillo, hormigón, metal, piedra, entre otros. Así mismo, utilizar otros inimaginables en nuestro contexto profesional como plásticos, textiles, vinílicos, polvos metalizados e incluso productos orgánicos (flores y alimentos).

Figura 8. Sustrato textil

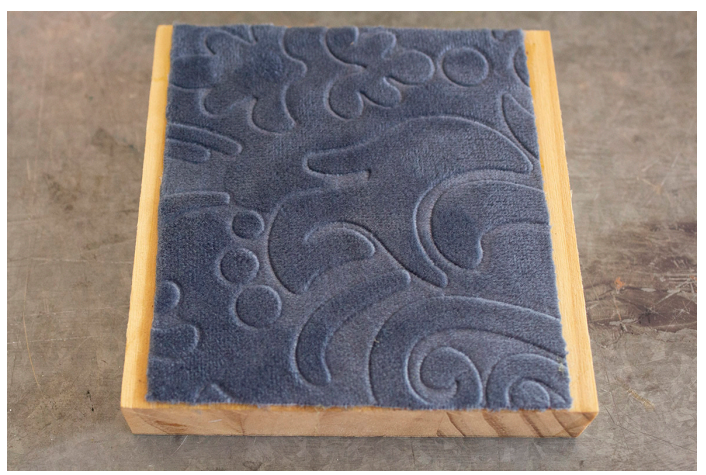

Fuente: Mejía \& Sigcha, (2020).

Figura 10. Sustrato de hormigón

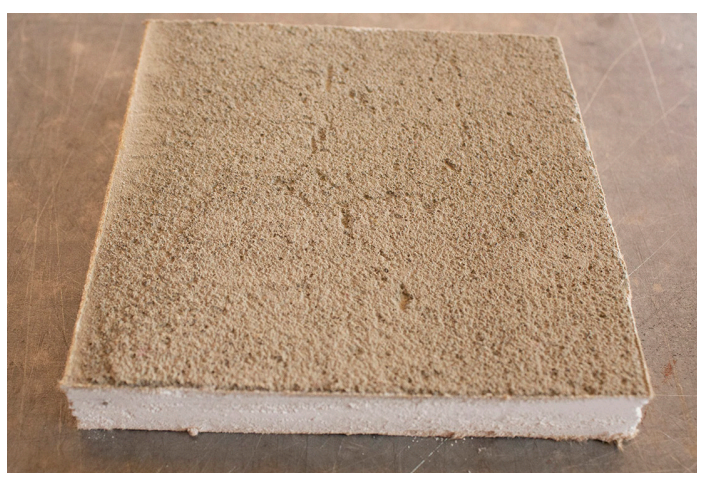

Fuente: Mejía \& Sigcha, (2020).
Figura 9. Sustrato en vinil adhesivo

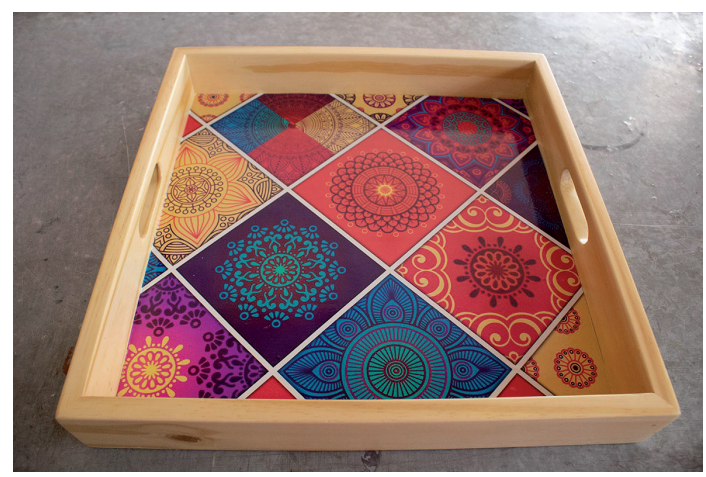

Fuente: Mejía \& Sigcha, (2020).

Figura 11. Sustrato de ladrillo

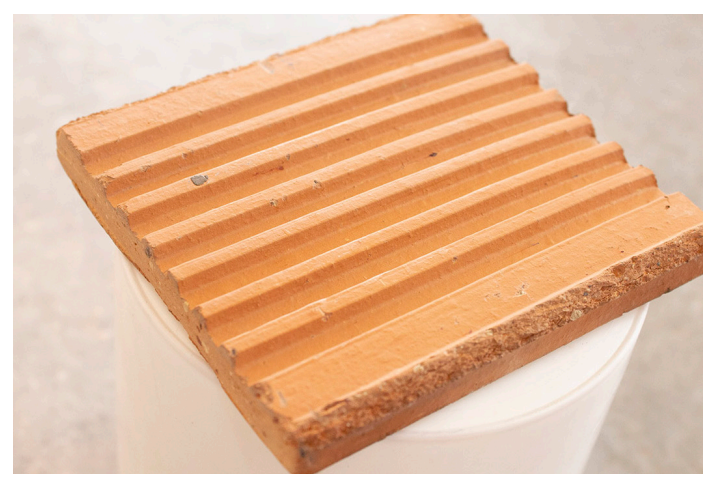

Fuente: Mejía \& Sigcha, (2020). 
Figura 12. Sustrato cerámico

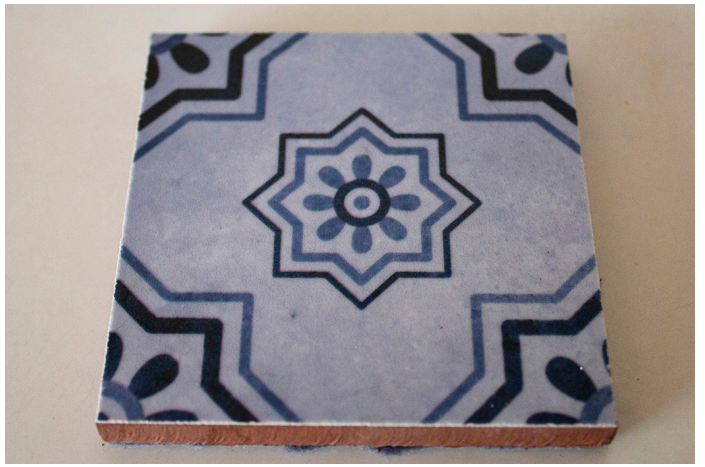

Fuente: Mejía \& Sigcha, (2020).

Es importante mencionar que se debería considerar el peso de los recubrimientos que no estén adheridos a la superficie. Por ejemplo, al momento de utilizar el plástico, en la práctica, descubrimos que tiene una tendencia a flotar. Nosotros

Figura 14. Experimentación pigmento metalizado y plástico

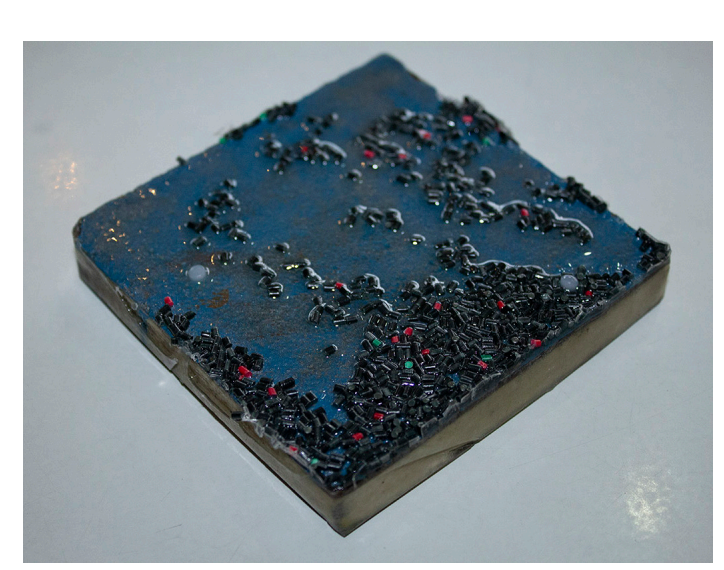

Fuente: Mejía \& Sigcha, (2020).
Figura 13. Sustrato en yeso y plástico

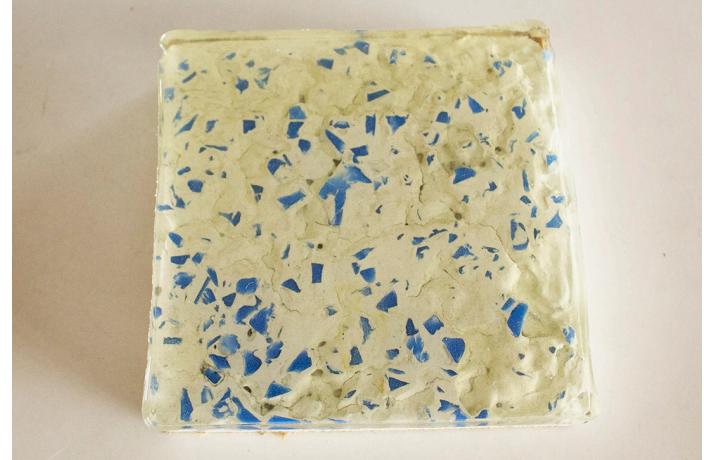

Fuente: Mejía \& Sigcha, (2020).

encontramos dos soluciones: la primera consiste en dejar reposar el epóxico durante un par de horas y, en ese momento, verter el plástico o material liviano; la segunda es adherir el recubrimiento a la zona a tratar para después aplicar el producto. 


\section{d. Aplicación de la pintura epóxica}

En este paso se debe considerar un correcto aislamiento de las zonas donde se aplicaría el producto; en áreas grandes (pisos) a más de su correcto tratamiento se debería cubrir las imperfecciones por donde podría fugar el material. Es importante considerar que, en acabados de la construcción como el entablado, no es conveniente usar el producto porque se derramará por las juntas de las duelas. Cuando se trabaja con madera, es importante considerar que requiere una ventilación por sus propie-

Figura 15. Moldeado con cartón

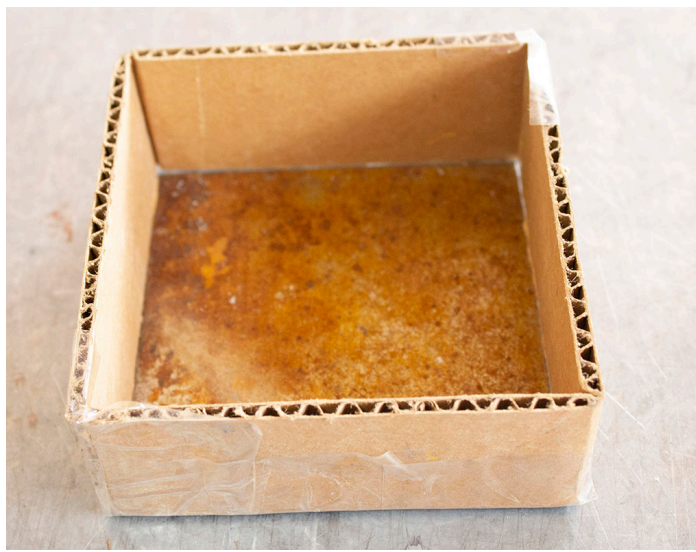

Fuente: Mejía \& Sigcha, (2020).

El epóxico, al ser un polímero termoestable, necesita de un catalizador para su endurecimiento. Su dosificación recomendada es 3:1, lo que significa que se necesita tres partes de base y una de catalizador, con lo que se obtiene un producto óptimo para su aplicación. La mezcla se deja reposar para una correcta homogeneización durante un par dades. En el caso de un piso de madera instalado sobre losa de hormigón y recubierto por un material impermeabilizante, hará que, por la imposibilidad de eliminar humedad, la madera se curve. En este caso es necesario trabajar la madera con un producto hidrófugo para corregir la ineficiencia de la pintura epóxica sobre este material. Por otra parte, en aplicaciones sobre elementos pequeños, se recomienda el uso de moldes para evitar fugas. Es importante añadir que, en caso de no contar con moldes, se podría emplear la cinta adhesiva de grado de construcción para lograr un encapsulado idóneo.

Figura 16. Moldeado con cinta adhesiva

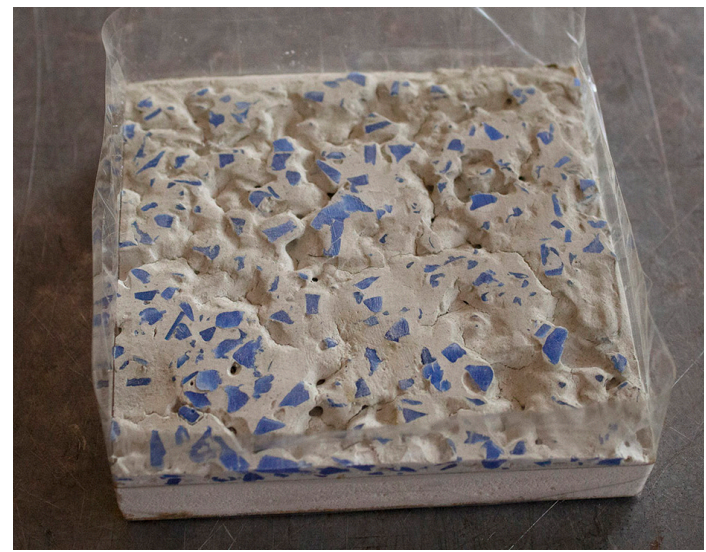

Fuente: Mejía \& Sigcha, (2020).

de minutos, entonces queda lista para la aplicación. Para un óptimo desempeño, la capa epóxica debe tener un grosor mínimo de $0.4 \mathrm{~cm}$. Cabe añadir que, en caso de utilizarse los polvos metalizados, se los agrega minutos antes a la mezcla reposada, después se vuelve a homogeneizar antes de aplicar a la superficie. 
Figura 17. Aplicación de pintura epóxica en bandeja de madera

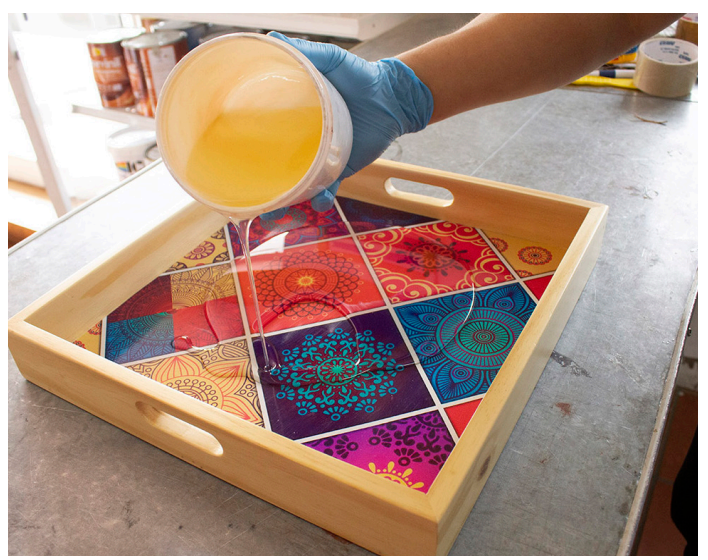

Fuente: Mejía \& Sigcha, (2020).

Figura 19. Aplicación de epóxico en varios sustratos

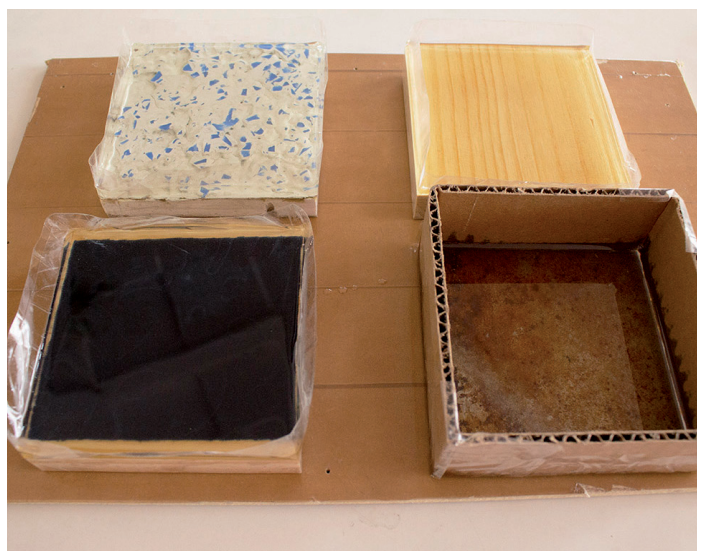

Fuente: Mejía \& Sigcha, (2020).

\section{e. Desmoldeo y curación}

El quinto paso consiste en deja fraguar el material durante aproximadamente cinco días. Posteriormente, se retiran las cintas, moldes y elementos que hemos utilizado previamente para evitar que
Figura 18. Aplicación de pintura

epóxica en tronco de madera

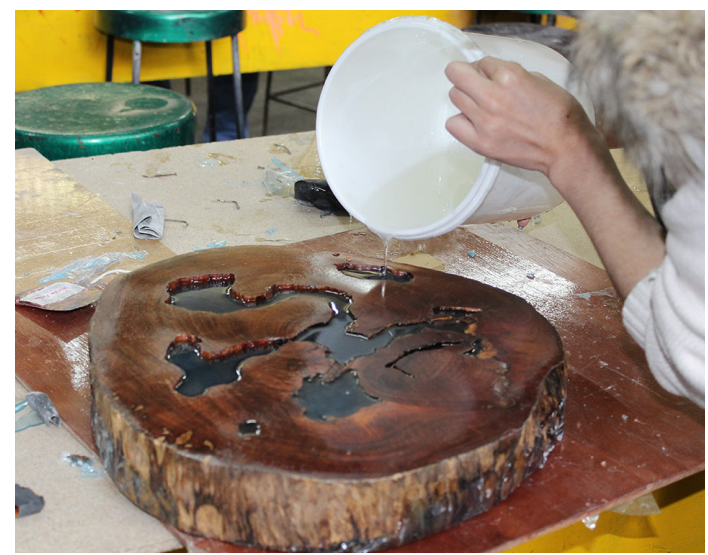

Fuente: Mejía \& Sigcha, (2020).

Figura 20. Aplicación de pintura epóxica pigmentada

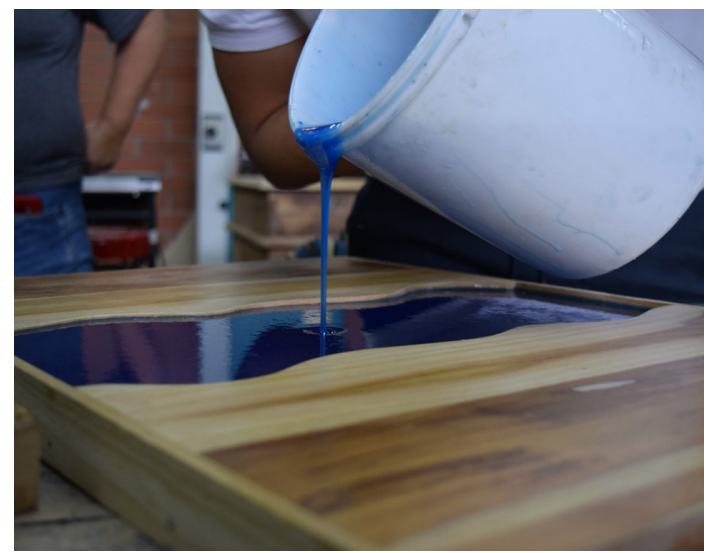

Fuente: Mejía \& Sigcha, (2020).

el epóxico salga de la zona de aplicación. En este punto, queda evidenciada la presencia de factores negativos tales como burbujas, trizaduras, rayones, asentamiento de polvo, entre otros. 
Figura 21. Desmoldeo de cinta

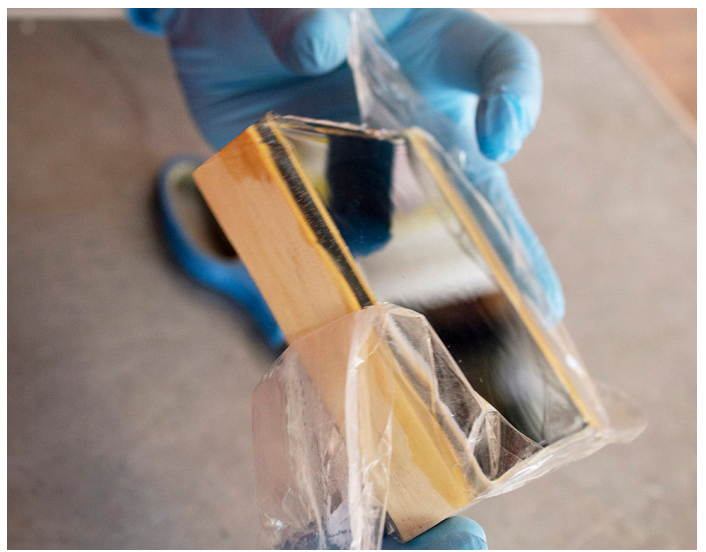

Fuente: Mejía \& Sigcha, (2020).

A continuación, inicia el proceso de curado que varía de acuerdo al tipo de problema, es por ello que en la experimentación encontramos tres soluciones principales: en el caso de burbujas se procede a

Figura 23. Curado

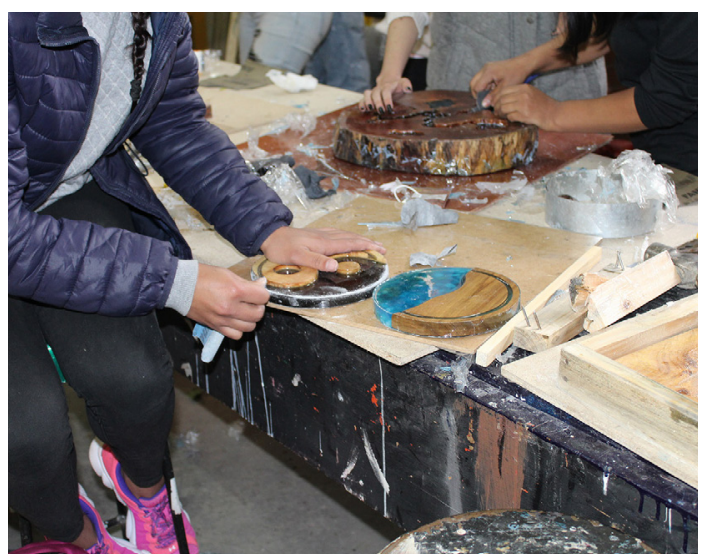

Fuente: Mejía \& Sigcha, (2020).

Por otra parte, en el caso de los agrietamientos, procedemos a lijarlos para volver a tener adherencia y enseguida vertemos otra capa de epóxico. En algunos casos especiales, cuando la fisura es profunda y ocasionada por la irregularidad de la superficie, se vuelve a aislar la zona de aplicación para evitar filtraciones.
Figura 22. Desmoldeo de cartón

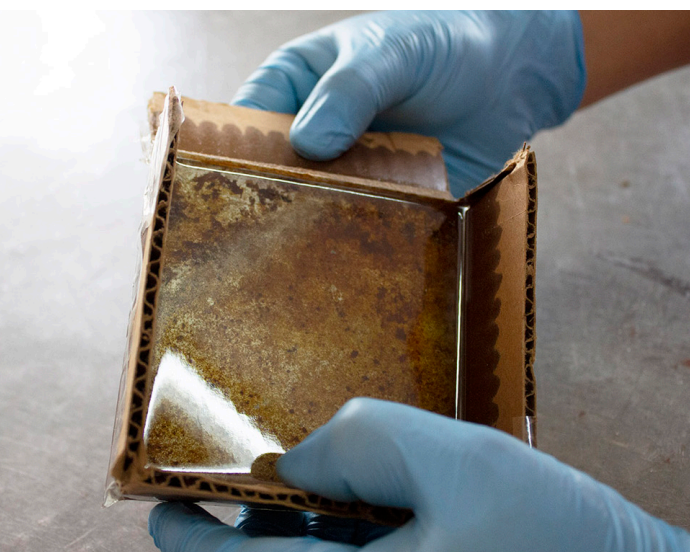

Fuente: Mejía \& Sigcha, (2020).

romperlas con un objeto cortopunzante y enseguida se realiza un proceso de lijado para alisar en gran medida la superficie dañada. Posteriormente, se limpian las impurezas y se lo rellena con epóxico nuevamente.

Figura 24. Pulido

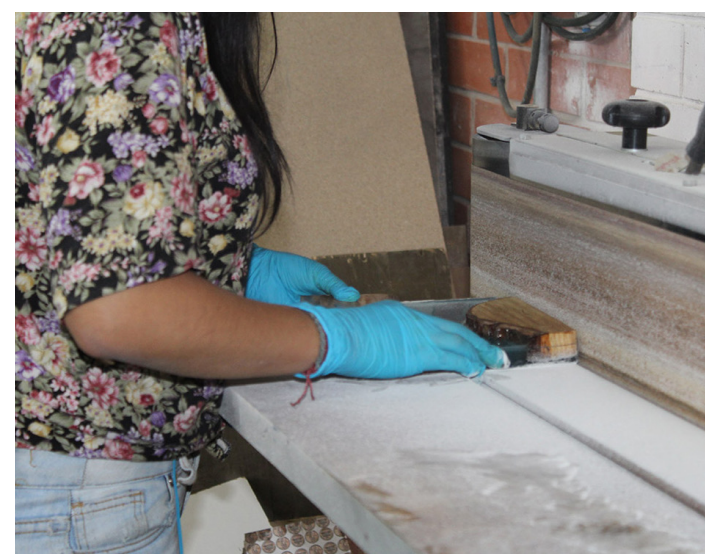

Fuente: Mejía \& Sigcha, (2020).

Finalmente, cuando tenemos problemas de asentamiento de polvos u otros objetos que no estuvieron previstos, se realiza un proceso completo de lijado que opaca la superficie y por ende se requiere un pulido. 


\section{f. Sellado}

El sexto paso, después de que se han curado todas las imperfecciones, es aplicar una fina capa de pintura epóxica con un rodillo o brocha. La capacidad de adherencia de la pintura permite una fuerte compactación con la capa anterior, la cual da mayor resistencia. De igual manera, presenta propiedades de impermeabilización, y logra repeler la humedad y los líquidos que podrían perpetrar, lo que facilitará el mantenimiento a futuro.

Figura 25. Sellado con barniz en aerosol

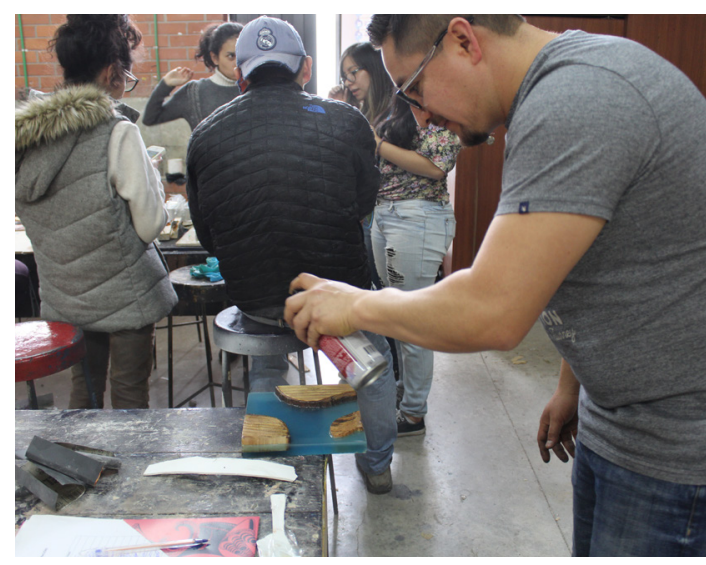

Fuente: Mejía \& Sigcha, (2020).

Figura 26. Sellado con brocha

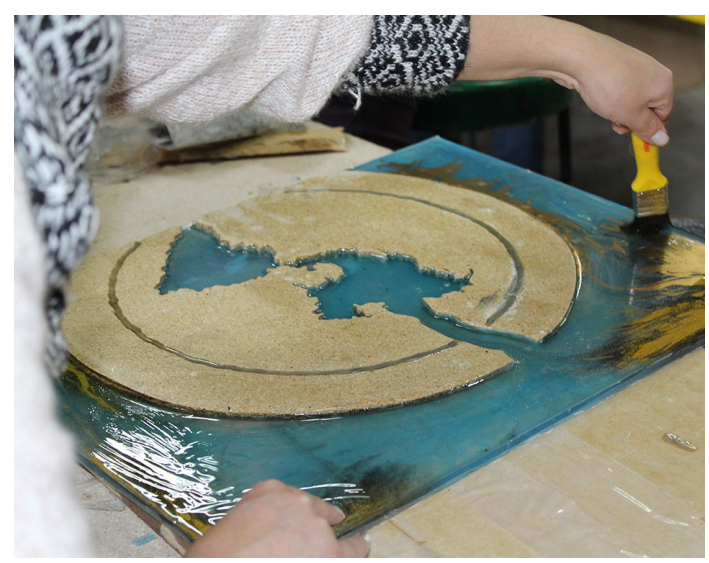

Fuente: Mejía \& Sigcha, (2020).
Figura 27. Sellado con rodillo

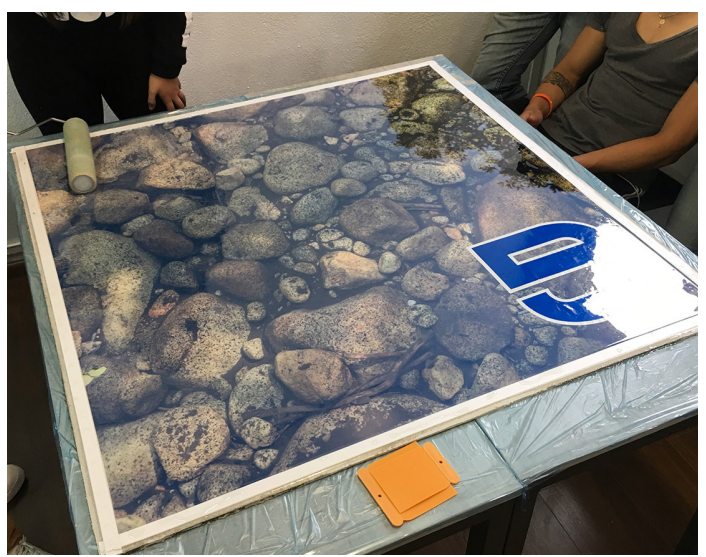

Fuente: Mejía \& Sigcha, (2020). 


\section{Resultados}

Después de la experimentación, pudimos comprobar las propiedades de la pintura epóxica y las deficiencias que se presentan en su aplicación en el campo del diseño y la arquitectura en casos reales, obteniendo los siguientes resultados:
Con respecto al poder anticorrosivo del material, comprobamos que esta propiedad permite fijar adecuadamente una base oxidada con la pintura epóxica, también detiene la corrosión eficazmente, y, por su viscosidad, las micropartículas de óxido no emergen a la superficie. Generalmente, la mayoría de pinturas que trabajan con bases oxidadas producen una reacción adversa, haciendo que los productos no se adhieran a la superficie tratada.

Figura 28. Epóxico aplicado en superficies corrosivas

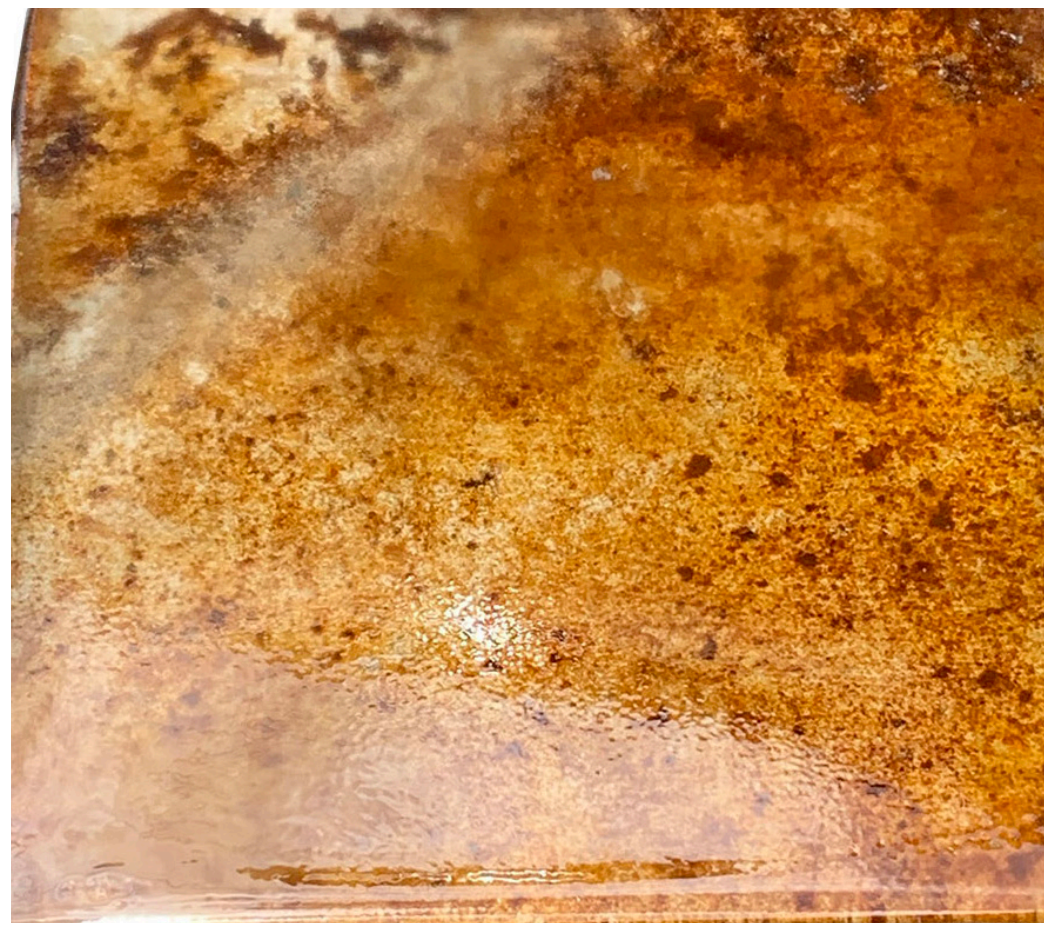

Fuente: Mejía \& Sigcha, (2020).

Seguidamente, pudimos verificar que la pintura epóxica reacciona adecuadamente con agentes externos como poliuretanos, betunes, aceites, entre otros. En este caso particular, verificamos su propiedad de alta resistencia química a los productos a base de aceite ya que, al verter el producto sobre la superficie trabajada con la substancia oleosa, se da una reacción poco común, se genera la encapsulación de las partículas; algo que finalmente, con el proceso de curado, obtiene el resultado final esperado. 
Figura 29. Reacción de pintura epóxica con productos base aceite

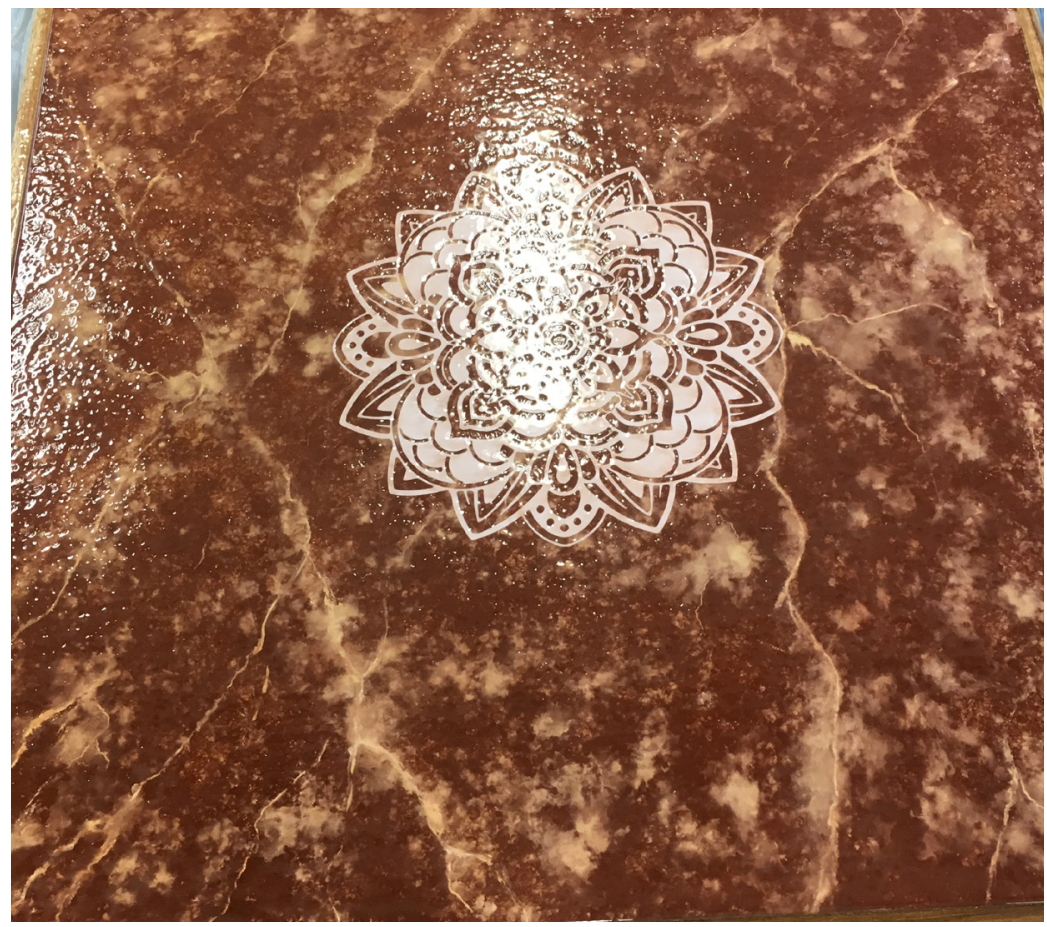

Fuente: Mejía \& Sigcha, (2020).

En lo que se refiere al esfuerzo y a la elasticidad, corroboramos esta propiedad en la aplicación del material en un cuarto de baño, vertemos la pintura epóxica sobre una superficie de hebras orientadas (OSB) que se encontraba conformando el piso. El principal objetivo es conocer las dos propiedades más importantes en este tipo de superficies: la impermeabilización, las propiedades hidrorepelentes y la elasticidad baja, debido a que el OSB presenta una maleabilidad media al someterse a peso.
El resultado evidencia un suelo que es resistente a productos de limpieza (detergentes 0 desinfectantes), así también observamos una menor maleabilidad de la superficie. Sin embargo, cuando el espacio está mojado, se pierde las propiedades antideslizantes, teniendo que realizarse un pulido especial para disminuir este defecto, lo que hace que se restituya la propiedad anteriormente mencionada. 
Figura 30. Pulido en espacios húmedos

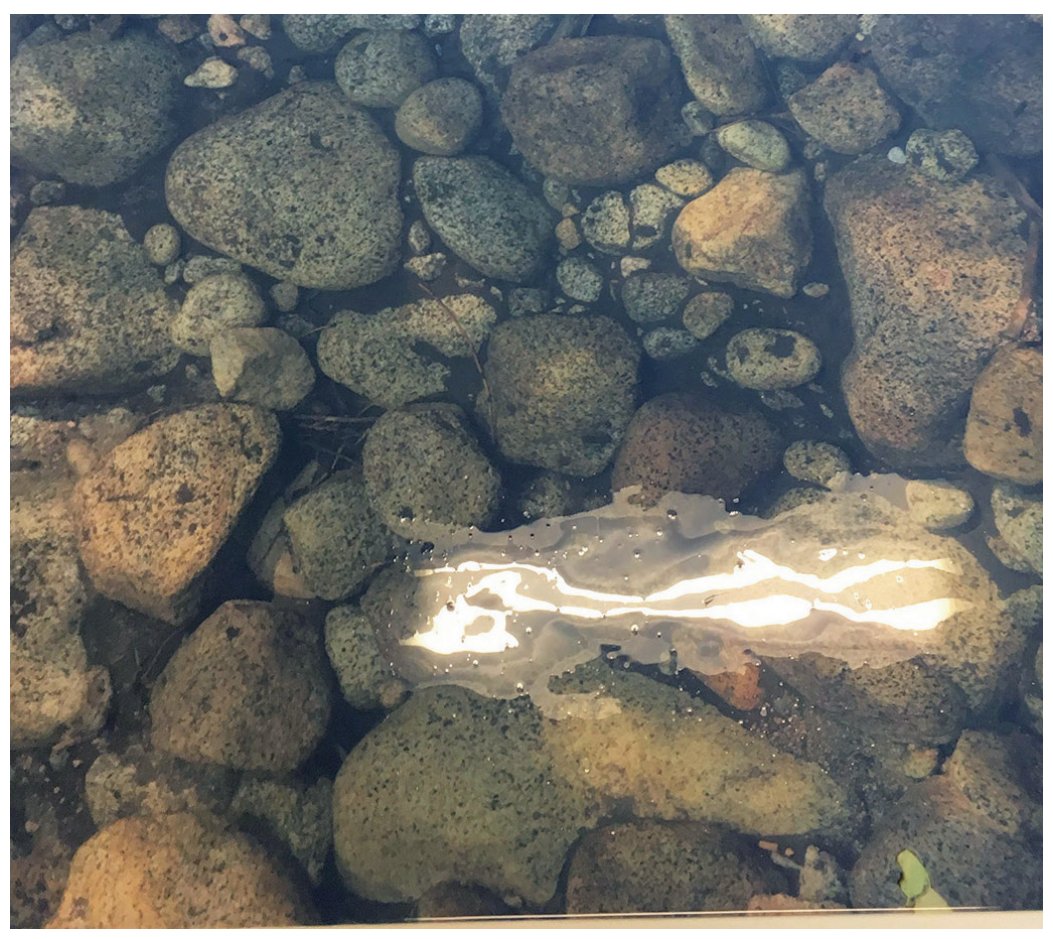

Fuente: Mejía \& Sigcha, (2020).

Con respecto a su capacidad de adherencia, con todo el proceso realizado se constató que la mayoría de los materiales, sean o no utilizados en el campo de la arquitectura y el diseño, son aptos para ser trabajados con la pintura epóxica. Es así que evidenciamos esta propiedad en materiales comu- nes como monedas, ladrillo y mortero adhesivo, así como en materiales inusuales como flores y textiles. A pesar de ser un producto químico, no se afectó físicamente a los productos orgánicos ni a otros sustratos con los que se trabajó. 
Figura 31. Epóxico con materiales inusuales, monedas

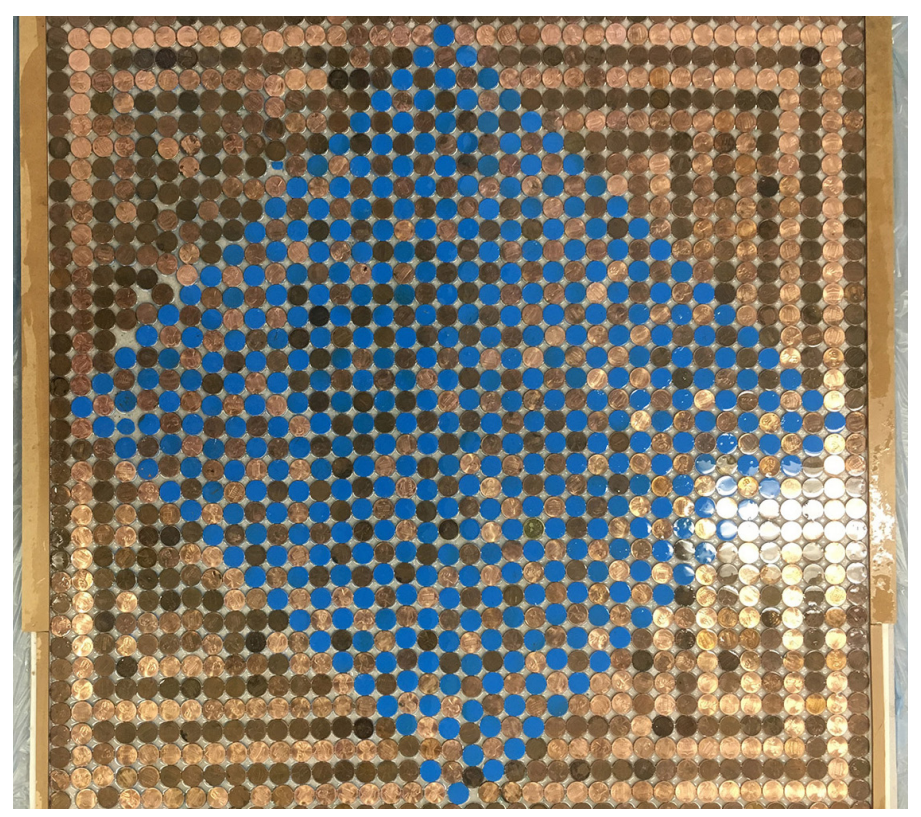

Fuente: Mejía \& Sigcha, (2020).

Figura 32. Epóxico con ladrillo industrial con textura

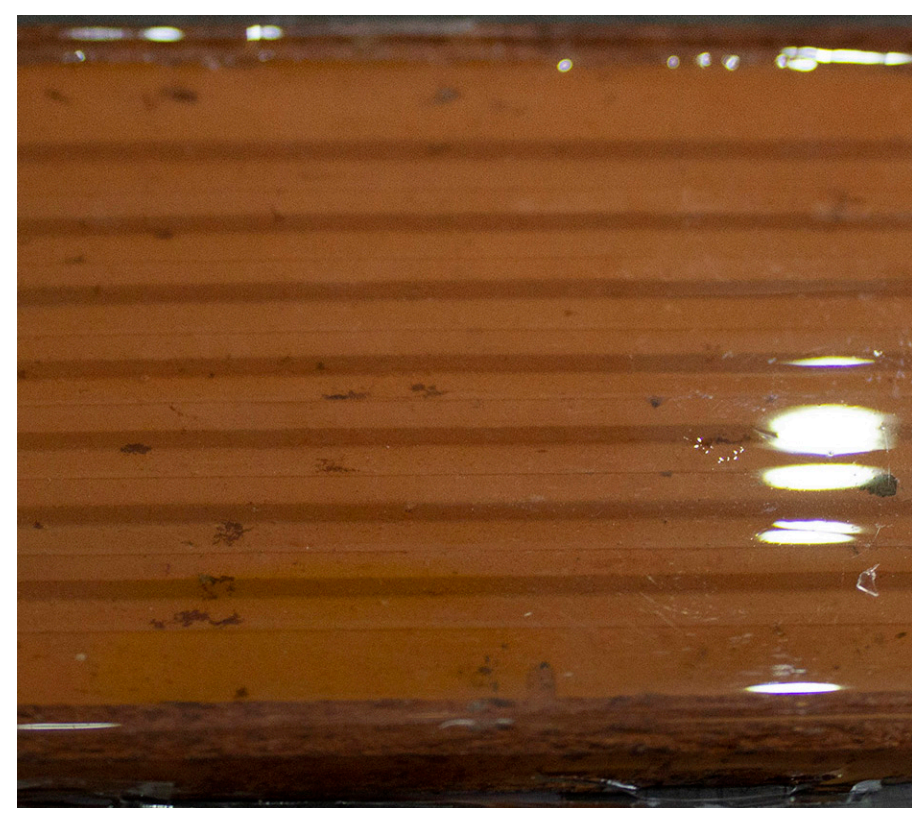

Fuente: Mejía \& Sigcha, (2020).

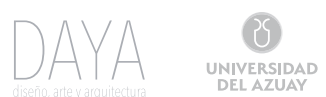


Figura 33. Epóxico aplicado en hormigón

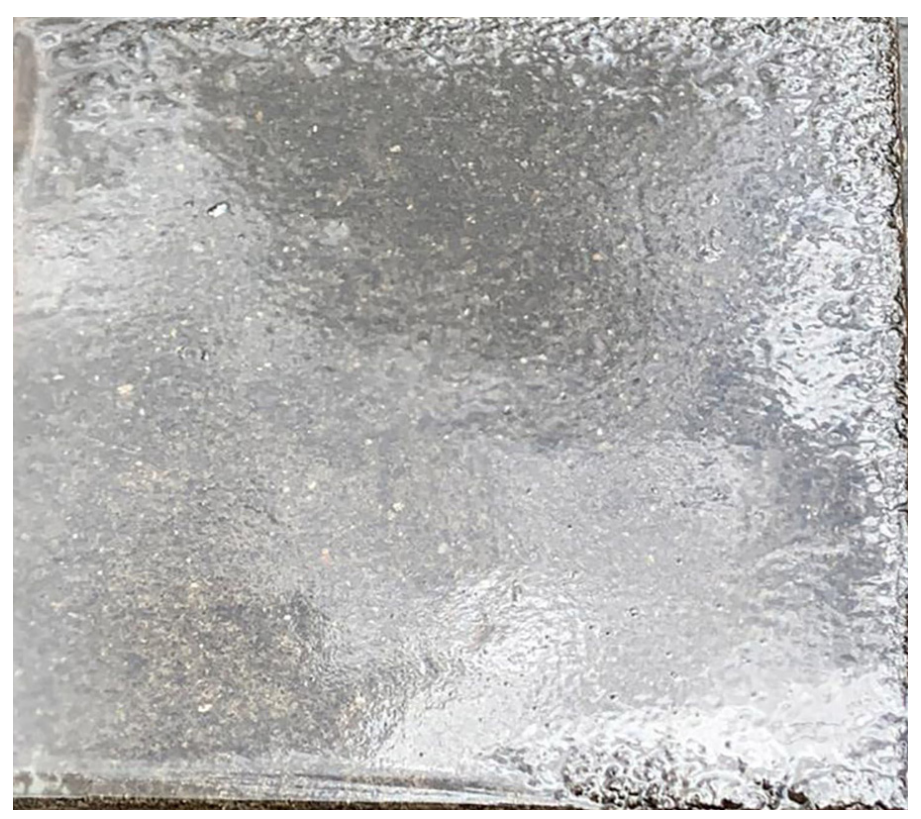

Fuente: Mejía \& Sigcha, (2020).

Ahora bien, después de ser analizadas las bondades y limitaciones, tanto del producto como del objeto a aplicar, hemos conocido algunas de sus reacciones tanto positivas como negativas: se puede trabajar con casi cualquier material. De la misma manera, su gran capacidad de pigmentación crea un múltiple abanico de posibilidades, con los que se puede dar variados tonos y expresiones a la pintura epóxica. 
Figura 34. Aplicación de epóxicos tinturados

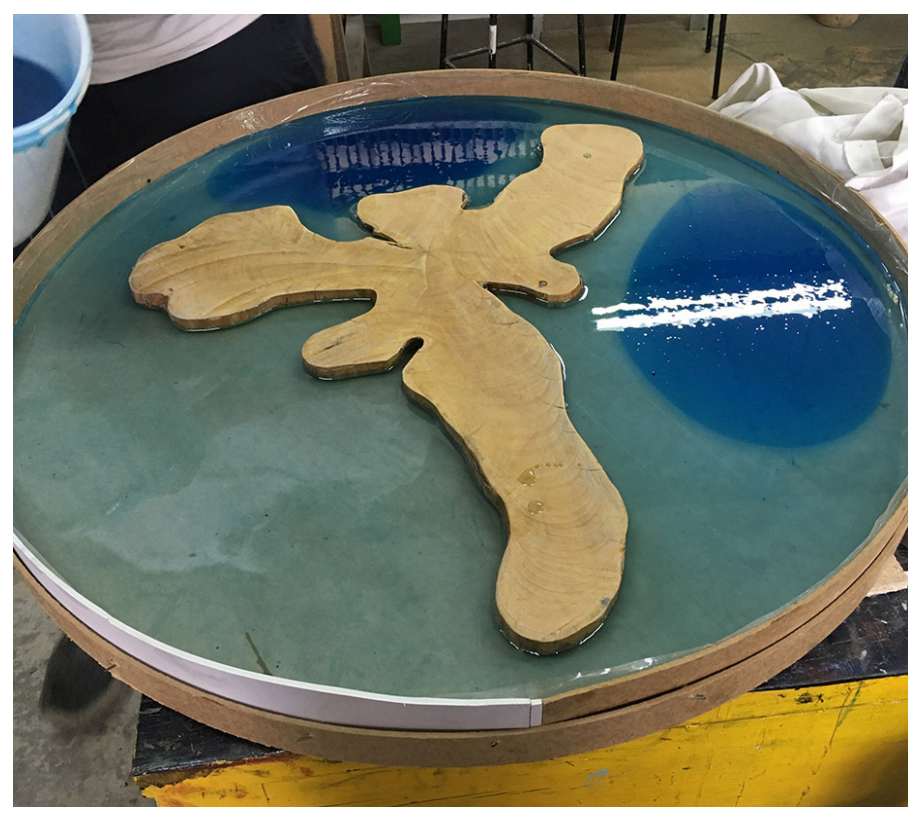

Fuente: Mejía \& Sigcha, (2020).

Figura 35. Homogeneización de epóxicos tinturados

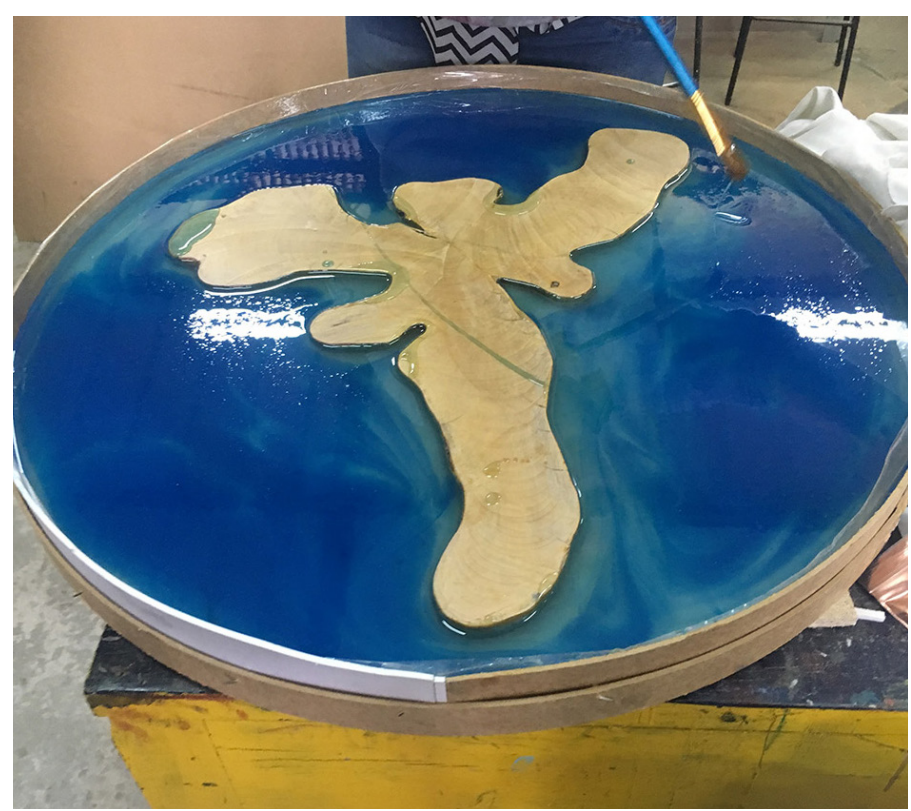

Fuente: Mejía \& Sigcha, (2020).

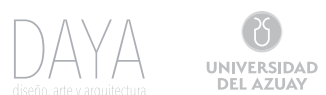


Figura 36. Resultado Final

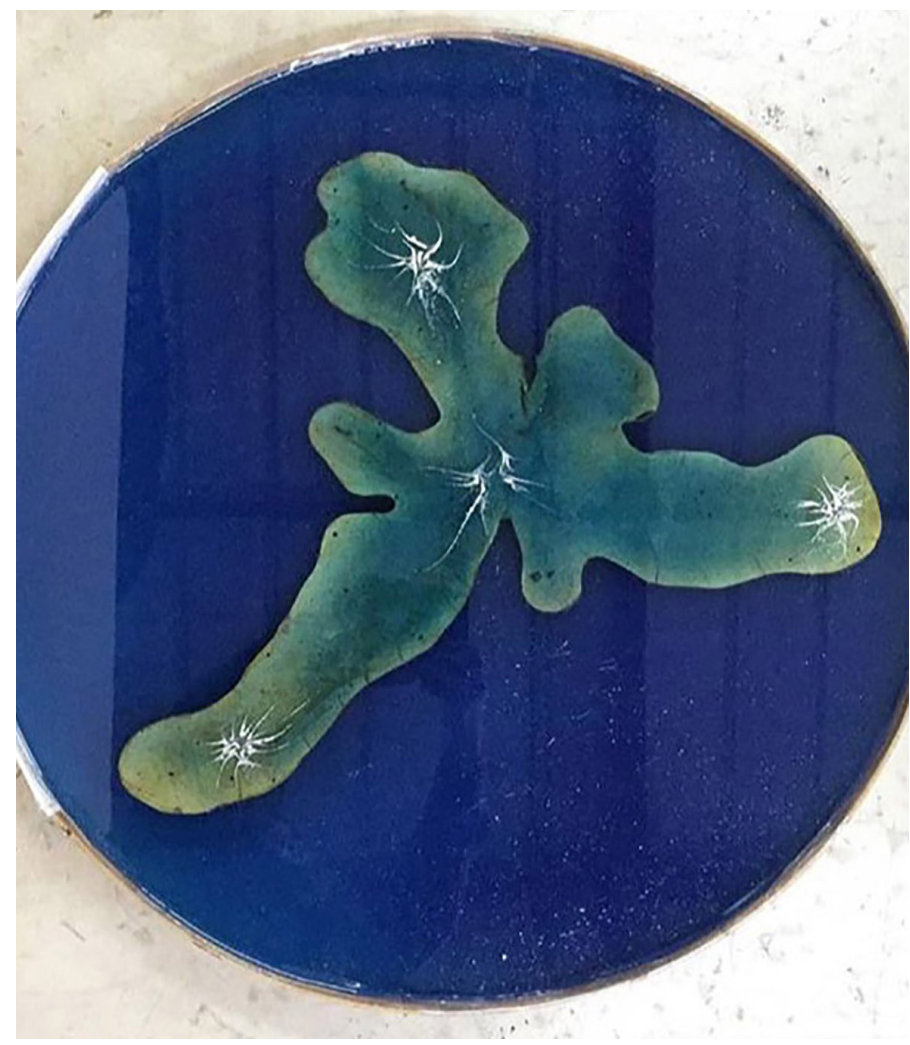

Fuente: Mejía \& Sigcha, (2020).

Con base en las consideraciones anteriores, pudimos determinar que las posibilidades decorativas se establecerán, en gran parte, por la estética que se pretenda obtener. La creatividad es un factor determinante que, bien aprovechado, puede generar excelentes resultados, que a nuestro criterio se convertiría quizá en la mejor herramienta.

\section{Conclusiones}

Atendiendo a los requerimientos constructivos impuestos por el medio y conociendo al producto en la mayoría de los ámbitos constructivos, podríamos concluir que la pintura epóxica constituye una solución totalmente aplicable no solo en el campo del diseño interior y la arquitectura, ya que algunas de sus propiedades podrían ser de gran ayuda en otros ámbitos como el arte, diseño de objetos, artesanía, textil e industrial. Mediante la experimentación, se pudo evidenciar que, con el proceso de encapsulado, se puede generar una amplia variedad de elementos de diseño contemporáneos como objetos, artículos e indumentaria. Resulta importante recalcar el fácil manejo del material, lo que permite su trabajabilidad y la incorporación de conceptos personales de los diseñadores. 
Por otra parte, se constató la escasez del producto en el mercado local y en algunos casos hay desconocimiento de su presencia en el mismo. Esto representa un factor desfavorable, ya que, al ser difícil de adquirir, convierte en exclusivas las propuestas, por lo que el producto se vuelve costoso y el uso del material, limitado. Sin embargo, la pintura epóxica ha demostrado ser un material que perdura por largo tiempo, lo que en cierta forma, representa un ahorro, al no requerir su reemplazo periódico. No obstante, desde el punto de vista ambiental, al no manipularlo correctamente genera impacto ecológico porque el ciclo de degradación es lento. Es por ello que debería practicarse una manipulación responsable y controlada.

Finalmente, el producto corrobora la importancia que tienen los materiales en la arquitectura y el diseño interior, ya que, como se pudo evidenciar, se pueden concebir propuestas con diversos conceptos y estéticas que influyen en cómo el usuario percibe el espacio: los profesionales de los campos mencionados ahora cuentan con una gran herramienta multifuncional. A nuestro juicio, la pintura epóxica se presenta como un recurso interesante que a futuro podría desatar una serie de nuevas experimentaciones de diversa índole.

\section{Referencias}

Ching, F., \& Binggeli, C. (2015). Diseño de Interiores: Un Manual.

Ecológico, E. M. (2018). ¿Cómo afecta el suelo de las industrias al medio ambiente? https://www. elmundoecologico.es/medio-ambiente/como-afecta-suelo-industrias-medio-ambiente/

Fernández Cánovas, M. (1964). Las resinas epoxi en la construcción. Informes de La Construcción, 16(159), 101-104. https://doi.org/10.3989/ic.1964.v16.i159.4570

García Diez, S. (2013). Recomendaciones, salud y seguridad en la manipulación de las resinas. Revista Iberoamericana de Polímeros, 14(5), 233-255. http://www.ehu.es/reviberpol/ SEPT13/garcia.pdf

Iturralde, D. C., \& Yagual, C. E. (2012). Diseño y desarrollo de pintura autonivelante epóxica base solvente.

Kumar, S., Samal, S. K., Mohanty, S., \& Nayak, S. K. (2018). Recent Development of Biobased Epoxy Resins: A Review. Polymer - Plastics Technology and Engineering. Taylor and Francis Inc. https://doi.org/10.1080/03602559.2016.1253742

Miravete, A. (1995). Los nuevos materiales en la construcción (Editorial). Barcelona. https://books. google.es/books?hl=es\&lr=\&id=utfov_vfPkMC\&oi=fnd\&pg=PA11\&dq=resina + epoxi+material+arquitectura\&ots=GdxZw3GiGM\&sig=ZLqhuAc6Ma1G63NHfL7P_hVI$\mathrm{hsE} \mathrm{E}=$ onepage \&q=resina epoxi material arquitectura\&f $=$ false

UGT.(2020). Riesgos en la manipulación de resinas epoxidadas. http://www.saludlaboral.ugtcyl.es/ riesgos-en-la-manipulacion-de-resinas-epoxidas

Vié, G. (1970). Interesantes aplicaciones de las resinas sintéticas en obras de ingeniería civil, 23.

\section{Figuras}

Figura 1. Ehowenespanol. (2017). Mapeado. https://www.ehowenespanol.com/arreglar-piso-hormigon-desmorona-como_356373/

Figura 2. Umacon. (2017). Agrietamiento. http://www.umacon.com/noticia.php/es/causas-y-soluciones-para-grietas-cemento/441 
Figura 3. Biounitcontrol. (2019). Moho. https://www.biounitcontrol.com/como-eliminar-moho-de-una-pared/

Figura 4. Mejía \& Sigcha. (2020). Aplicación de sellador en aerosol sobre hormigón

Figura 5. Mejía \& Sigcha. (2020). Aplicación de sellador en aerosol sobre ladrillo.

Figura 6. Mejía \& Sigcha. (2020). Aplicación de ligante sobre hormigón.

Figura 7. Mejía \& Sigcha. (2020). Aplicación de imprimante sobre hormigón.

Figura 8. Mejía \& Sigcha. (2020). Sustrato textil.

Figura 9. Mejía \& Sigcha. (2020). Sustrato en vinil adhesivo.

Figura 10. Mejía \& Sigcha. (2020). Sustrato de hormigón.

Figura 11. Mejía \& Sigcha. (2020). Sustrato de ladrillo.

Figura 12. Mejía \& Sigcha. (2020). Sustrato cerámico.

Figura 13. Mejía \& Sigcha. (2020). Sustrato en yeso y plástico.

Figura 14. Mejía \& Sigcha. (2020). Experimentación pigmento metalizado y plástico.

Figura 15. Mejía \& Sigcha. (2020). Moldeado con cartón.

Figura 16. Mejía \& Sigcha. (2020). Moldeado con cinta adhesiva.

Figura 17. Mejía \& Sigcha. (2020). Aplicación de pintura epóxica en bandeja de madera.

Figura 18. Mejía \& Sigcha. (2020). Aplicación de pintura epóxica en tronco de madera

Figura 19. Mejía \& Sigcha. (2020). Aplicación de epóxico en varios sustratos.

Figura 20. Mejía \& Sigcha. (2020). Aplicación de pintura epóxica pigmentada.

Figura 21. Mejía \& Sigcha. (2020). Desmoldeo de cinta.

Figura 22. Mejía \& Sigcha. (2020). Desmoldeo de cartón.

Figura 23. Mejía \& Sigcha. (2020). Curado.

Figura 24. Mejía \& Sigcha. (2020). Pulido.

Figura 25. Mejía \& Sigcha. (2020). Sellado con barniz en aerosol.

Figura 26. Mejía \& Sigcha. (2020). Sellado con brocha.

Figura 27. Mejía \& Sigcha. (2020). Sellado con rodillo.

Figura 28. Mejía \& Sigcha. (2020). Epóxico aplicado en superficies corrosivas.

Figura 29. Mejía \& Sigcha. (2020). Reacción de pintura epóxica con productos base aceite.

Figura 30. Mejía \& Sigcha. (2020). Pulido en espacios húmedos.

Figura 31. Mejía \& Sigcha. (2020). Epóxico con materiales inusuales, monedas.

Figura 32. Mejía \& Sigcha. (2020). Epóxico con ladrillo industrial con textura.

Figura 33. Mejía \& Sigcha. (2020). Epóxico aplicado en hormigón.

Figura 34. Mejía \& Sigcha. (2020). Aplicación de epóxicos tinturados.

Figura 35. Mejía \& Sigcha. (2020). Homogeneización de epóxicos tinturados.

Figura 36. Mejía \& Sigcha. (2020). Resultado Final. 